\title{
O audiovisual como fonte de informação na escola: desafios para a media literacy
}

\author{
The audiovisual as a source of information in school: challenges for media literacy
}

\author{
Mariana Pícaro Cerigatto \\ Doutoranda do Programa em Ciência da Informação da UNESP, campus Marília \\ E-mail: maricerigatto@yahoo.com.br
}

Helen de Castro Silva Casarin

Doutora em Letras pela UNESP.

Professora do Departamento de Ciência da Informação da UNESP, campus de Marília.

E-mail: helenc@ marilia.unesp.br

\begin{abstract}
Resumo
O objetivo deste artigo é explanar sobre as produções audiovisuais como fontes de informação e pesquisa nas bibliotecas escolares e recurso didático nas escolas. O texto discorre sobre a leitura audiovisual procedente tanto de mídias já conhecidas, como as mais tradicionais, e também discute brevemente fenômenos atuais que ocorrem com o audiovisual na internet. Ainda apresenta conceitos-chaves para o trabalho com a media literacy e a competência midiática, que dão bases para a leitura crítica de textos audiovisuais midiáticos. Discute-se também a necessidade de abandonar a visão de que as mídias audiovisuais estão corrompendo as mídias impressas, e que a televisão e o cinema, assim como a internet, são uma ameaça para o ambiente escolar. Fala-se da importância de reformular o papel da biblioteca, que precisa admitir outros meios de acesso à informação e agregá-los de forma mais consistente em seu ambiente. Espera-se, com este trabalho, que o professor possa ir além do uso ilustrativo da imagem e do audiovisual, que geralmente é o mais recorrente em sala de aula quando se utilizam esses meios.
\end{abstract}

Palavras-chave: media literacy. competência midiática. leitura audiovisual. fontes de informação

\begin{abstract}
The purpose of this article is to explain about the audiovisual productions as sources of information and research in school libraries and teaching resource in schools. The paper is about the coming audiovisual reading both known media, as the more traditional, and also briefly discusses current phenomena that occur with audiovisual on the internet. The text also presents key concepts to work with literacy media and the media literacy, which provide basis for critical reading of media audiovisual texts. It also discusses the need to abandon the view that the audiovisual media are corrupting the print media, and television and film, as well as the internet, are a threat to the school environment. There is talk also of importance to reformulate the role of the library, which have to admit other means of access to information and aggregate them more consistently in your environment. Hopefully, with this work, the teacher can go beyond the illustrative use of the image and the audiovisual sector, which is usually the most recurrent in the classroom when using these means.
\end{abstract}

Keywords: media literacy. audiovisual reading. information sources

Bibl. Esc. em R., Ribeirão Preto, v. 3, n. 2, p. 31-52, 2015. 


\section{Introdução}

Vivemos a chamada "revolução" técnica de produção e reprodução de textos diante o cenário digital. Neste contexto, vários novos textos surgem e modificam até então o que conhecíamos de suas linguagens. Não são somente mudanças no suporte, mas no próprio hábito de ler.

Desta conjuntura, surgem muitas indagações, tanto para leitores quanto para mediadores de leitura. Os livros impressos vão acabar? A linguagem não verbal, mais atrativa e muito presente nas novas mídias, vai se sobrepor de vez à linguagem verbal? Como entender as linguagens que já se tornaram tão comuns no nosso cotidiano, mas não temos ideia de como elas funcionam? Como se tornar leitor crítico delas, e ainda, como se apropriar delas para produzir mensagens em meio das facilidades e possibilidades advindas do mundo digital? Afinal, hoje em dia não somos apenas meros leitores, temos a oportunidade de produzir informações com as mais variadas tecnologias.

O objetivo deste artigo é explanar a importância que a produção audiovisual (filmes, minisséries, novelas etc.) assume como fonte de informação e pesquisa escolar. E, com a internet, amplia-se a variedade de novas produções. $O$ texto discorre sobre a leitura audiovisual, procedente tanto de mídias já conhecidas, como as mais tradicionais, e também aponta brevemente alguns dos fenômenos atuais que ocorrem com o audiovisual na internet. Apresenta-se, ainda, um tópico sobre a media literacy e a competência midiática, com a caracterização dos conceitos-chaves necessários para a leitura crítica de textos audiovisuais midiáticos, inclusive procedentes dos meios de comunicação de massa.

\section{A televisão e o cinema como fontes de informação e pesquisa escolar}

A TV é um meio de comunicação bastante popular e presente nos lares brasileiros, e às vezes é tida como a única fonte de lazer de várias famílias. Por isso, possui papel importante na composição do sistema comunicativo midiático contemporâneo. Bretas (2008, p. 89) evidencia que:

O papel desempenhado pela TV pode ser analisado por intermédio de suas funções informativa, formativa e de entretenimento. A primeira função, informativa, baseiase na busca e difusão de notícias, marcadas pelo caráter de atualidade, de novidade e pelas mensagens que envolvem e situam a vida das pessoas. 
Mariana Pícaro Cerigatto e Helen de Castro Silva Casarin

Para Kenski (2005), a televisão está cada vez mais atrelada à realidade cotidiana. E, nesta perspectiva, seu significado e papel vão além de uma mera tecnologia. As pessoas se relacionam com a TV como complemento, companhia e continuação do espaço de vida. Por meio do que é transmitido, tomam decisões a partir informações e transformam seus comportamentos. Apesar de várias pesquisas apontarem uma recepção ativa, que negocia com o conteúdo midiático, muitos ainda conservam a posição passiva diante do que é veiculado, sem questionamentos e reflexão.

Mas, com a internet, temos uma gama maior de produções audiovisuais, que inclusive se sobrepõe e inova o que é veiculado pela televisão massiva. Então, justifica-se descartar a TV? Para Kenski (2005), há a concepção de que a televisão e o vídeo estão ultrapassados, e já não são mais tão importantes. Parece que já foram superadas suas linguagens e sua utilização na educação. Contudo, a televisão, como já dita, ainda é um meio importante e de presença muito forte nos lares brasileiros. De acordo com Moran (2005, p. 97), "a informação e a forma de ver o mundo predominantes no Brasil provêm fundamentalmente da televisão. Ela alimenta e atualiza o universo sensorial, afetivo e ético que crianças e jovens - e grande parte dos adultos - levam a para sala de aula".

Documentários, novelas, telejornais, curta-metragem, seriados, programas de auditório... mas, quando falamos de televisão como fonte midiática, de pesquisa escolar, o que considerar? Para Farias Júnior (2014), é importante reconhecer os gêneros televisivos na escola, já que eles são responsáveis pelas representações que boa parte dos estudantes tem de mundo. Kuhlthau (2004) considera que uma das principais fontes de informação de uma criança é a televisão. Dentre as abordagens pedagógicas possíveis, a pesquisadora propõe mostrar que a televisão, da mesma maneira que a biblioteca, apresenta materiais de ficção e não ficção:

\footnotetext{
Ao assistir programas de ficção, a criança envolve-se em seus sentimentos e sua imaginação flutua com pouco esforço consciente. A experiência vivida naquele momento, durante o programa, é importante. Em programas de não ficção, a atenção da criança deve estar mais concentrada e dirigida para o ponto central e para a informação apresentada (KUHLTHAU, 2004, p. 150).
}

Outro caminho é o da comparação entre informações e narrativas que vêm do livro e da televisão. Ao ler histórias que as crianças já tiveram contato através da televisão ou em vídeo, é possível identificar contrastes e diferenças entre as experiências com a mesma história através de cada meio. Entendem que o que viram na televisão não pode substituir o que leram nos livros, e vice-versa. $\mathrm{O}$ audiovisual oferece uma experiência visual, que pode 
O audiovisual como fonte de informação na escola: desafios para a media literacy

ajudar a compreender uma informação, o que não pode ser dada por materiais impressos. Por outro lado, o livro detém de uma informação detalhada e aprofundada. O audiovisual não acompanha o ritmo do pensamento individual; se não é possível rever o vídeo, a informação é perdida, diferente do que ocorre com o impresso. "Cada meio afeta o pensamento de forma diferente. Em nossa cultura aprendemos utilizando vários meios" (KUHLTHAU, 2004, p.77).

E ainda, a comparação entre fontes ajuda a avaliar a relevância da informação que tem significado pessoal para cada estudante. Ao ver TV, pode-se relacionar e contestar o que se vê de acordo com informações que fazem parte do repertório individual, de outras fontes. E, então, ocorre a produção de sentido. "Dessa forma, podem descobrir que alguns programas de televisão têm pouco sentido para eles e podem entender, avaliar e selecionar melhor os programas mais significativos" (KUHLTHAU, 2004, p. 271).

Assim:

\begin{abstract}
As atividades que se seguem a uma apresentação audiovisual, da mesma maneira que aquelas que se seguem a uma história, dão às crianças oportunidades de expressar os significados do que viram, relacionando-os com suas experiências anteriores. Dessa forma, aprendem a compreender o que viram e começam a analisar e avaliar o papel da televisão e de outros meios de comunicação em suas vidas (KUHLTHAU, 2004, p. 77).
\end{abstract}

Ainda falando da televisão como fonte, Bretas (2008) evidencia sua função formadora, que está ligada às possibilidades educativas do meio. Existem, inclusive em emissoras abertas e ditas educativas, programações que versam conteúdos trabalhados no sistema formal de ensino, assim como programas voltados para promover a capacitação de determinados segmentos de público.

Contudo, nem sempre os referenciais que vêm da televisão são de emissoras estritamente educativas. Por isso, discutir a comunicação de massa que está muito presente neste meio é tarefa essencial dos educadores, pois, conforme já foi mencionado, a TV atua como formadora de opinião e é importante fonte de informação.

Apesar da Constituição Federal Brasileira de 1988 afirmar que a programação das emissoras de rádio e televisão deve dar preferência a finalidades educativas, culturais e informativas; e promover a cultura nacional e regional- estimulando a produção independente que a divulgue - a maioria dos canais abertos destina boa parte de sua programação voltada para conteúdos que investem na distração, ao lazer e ao preenchimento do tempo livre do público. 
Mariana Pícaro Cerigatto e Helen de Castro Silva Casarin

Porém, faz-se aqui uma observação: um conteúdo voltado para o entretenimento não pode conter informação considerada relevante? Bretas (2008, p. 89) discorre a esse respeito:

A informação noticiosa tanto atua na formação dos públicos quanto pode ser
apreciada na perspectiva do entretenimento. Conteúdos notadamente de
entretenimento também preenchem funções informativas e formativas. Junto a esse
conjunto de papéis desempenhados, a televisão coloca-se como espaço de expressão
de ideias e de motivação dos públicos ao consumo de bens, de serviços, de valores e
de crenças.

Portanto, fica claro que a escola pode se apropriar dos mais variados formatos e gêneros televisivos, totalmente voltados para o entretenimento ou não. O importante é tirar proveito educativo e construir uma perspectiva crítica sobre esses conteúdos. Aliás, essa é uma das tarefas da media literacy, ou da competência midiática.

Existem muitas possibilidades didáticas com o audiovisual tendo-o como fonte de informação e conhecimento. Farias Junior (2014) aponta que as diversas produções audiovisuais nos permitem dialogar e conhecer diferentes maneiras de representação simbólica (gráficos, textos, notas musicais, ícones, imagens). Além do mais, filmes, novelas etc. podem gerar outras narrativas bem diferentes em relação às informações dos livros, revistas e jornais da mídia impressa, o que nos permite comparar discursos e apreender significados diferentes, de acordo com o meio. Por isso, é importante ainda fazer uma análise comparativa e aliar o audiovisual à consulta de outras fontes, especialmente às fontes primárias. A intenção aqui não é desqualificar tais mídias, “[...] mas ajudar os alunos a perceber que se trata de um jogo de representações que devem ser entendidas criticamente para que eles construam o conhecimento histórico" (FARIAS JÚNIOR, 2014, p. web).

O mesmo autor ainda enfatiza a importância documental e histórica do audiovisual em sala de aula, que "[...] não só oferecem-nos pistas para pensar os motivos pelos quais as fontes audiovisuais em geral são tão envolventes, mas também sinalizam o alargamento da concepção de fonte histórica e estratégias de análise documental” (FARIAS JUNIOR, 2014, p. web).

Nesta concepção, o educador encontra à sua disposição, mesmo na mídia massiva, um leque significativo de opções, como minisséries e telenovelas que fizeram abordagens de temas históricos, transmitidos por emissoras de televisão brasileiras. No rol de filmes de interesse histórico podemos indicar até os animados: Pocahontas, A Família Dinossauro, Hércules e Flinstones, entre várias outras produções, nacionais e internacionais. 
O audiovisual como fonte de informação na escola: desafios para a media literacy

As produções audiovisuais podem ter sua importância como fontes para outras áreas disciplinares, podendo a escola e os professores usar a televisão dentro de um trabalho que agregue várias disciplinas. Além do valor histórico, uma produção audiovisual pode ser usada como fonte de pesquisa para as aulas de arte, por exemplo, para apreciação dos elementos estéticos, a combinação entre eles, quais elementos agradam e atraem tanto. O filme Titanic, por exemplo, que alcançou recorde de bilheteria. Como são combinados os elementos estéticos deste filme? Qual é a trilha sonora, como ela se combina com as cenas, como é o jogo de iluminação, as cores, os efeitos especiais etc., e como cada recurso desse cria uma sensação diferente de apreciação? O que desperta o riso, o choro, a emoção?

Essas atividades podem estar relacionadas ao trabalho em conjunto de professores de língua portuguesa, que podem apontar quais recursos da linguagem colocam em evidência a mensagem. Variadas novelas, filmes e minisséries também fazem adaptação de grandes clássicos da literatura, e o professor tem aí uma rica oportunidade de discutir como são feitas essas adaptações, os outros sentidos gerados pela obra, como a televisão ou o cinema fizeram para representar tal ideia da obra original etc.

O ideal, como se pode constatar, é que o professor tire proveito educativo dessas produções ao trabalhar como fonte de pesquisa e investigação em sala de aula; porém, geralmente, os educadores costumam contrapor a mídia e a escola. A escola educa, enquanto a TV 'deseduca' ou somente entretém. Sobre isso, Moran (2005), p. 97, ressalta que:

\footnotetext{
Justamente porque a televisão não diz que educa o faz de forma mais competente. Ela domina os códigos de comunicação e os conteúdos significativos para cada grupo: pesquisa-os, aperfeiçoa-os, atualiza-os. Nós, educadores, fazemos pequenas adaptações, damos um verniz de modernidade nas nossas aulas, mas fundamentalmente continuamos prendendo os alunos pela força e os mantemos confinados em espaços barulhentos, sufocantes, apertados e fazendo atividades pouco atraentes. Quem educa quem a longo prazo?
}

Sabe-se da existência de diversos programas que valorizam o trabalho com as mídias e o audiovisual como fonte de informação e conhecimento na escola e bibliotecas. O governo federal criou, na década de 1990, três iniciativas principais: a TV Escola, o DVD Escola e o Programa Nacional de Tecnologia Educacional (ProInfo). Dentre outras dezenas de exemplos, vale citar o projeto "O Cinema vai à Escola", que integra o programa "Cultura é Currículo", do governo do Estado de São Paulo. Iniciativas como essas mostram o reconhecimento do potencial didático de filmes e outros produtos audiovisuais. Porém, além da necessidade da formação do professor contemplar o trabalho com as mídias, é preciso que a escola, como um todo, ainda reconheça a necessidade de introduzir essas mídias e linguagens em seu projeto 
Mariana Pícaro Cerigatto e Helen de Castro Silva Casarin

pedagógico, com metodologia. Geralmente, segundo alerta Pires (2010, p. 283), o trabalho com as mídias audiovisuais

[...] induz a interesses e comportamentos que perturbam o seu quadro habitual conformado pelas velhas práticas que há muito tempo atuam com uma racionalização disciplinadora, separando os saberes - idades, o pensar do sentir, o trabalho do ócio. Ao contrário, a cultura midiática não separa o sensível do inteligível; a atividade reflexiva do entretenimento.

Isso nos leva a pensar o modo como são desenvolvidas e implementadas as ações pedagógicas para ensinar mídia, que variam de acordo com a concepção que os educadores e comunicadores têm dessa área. De acordo com Green e Hannon (2007), as posturas para educar para mídia ora tendem a cair na fé cega na tecnologia (para quem a simples presença das mídias e tecnologias na escola, em si mesma, já é algo revolucionário e positivo) e ora tendem a assumir uma postura que se aproxima do chamado "pânico moral" (para quem a cultura trazida pelas mídias é uma degeneração que deve ser combatida pela educação escolar). Entre esses dois lados extremos, pode-se recorrer a uma série de posturas mais equilibradas. Buckingham (2003) aponta que, ao trabalhar com as mídias, não se deve promover nem "inocular" - mas sim preparar as pessoas para usá-las com mais proveito, tanto como consumidoras, quanto como cidadãs (CERIGATTO, SIQUEIRA, 2008).

Ao adotar uma postura equilibrada, podemos levar para a sala de aula até as telenovelas, como "Salve Jorge", de autoria da escritora Gloria Perez, exibida entre os anos de 2012 e 2013 por uma emissora de televisão brasileira, em horário considerado "nobre". A novela discutiu a questão do tráfico humano. Apesar de trazer à tona um tema atual, a produção recebeu críticas por retratar, por vezes, a temática de maneira bem fantasiosa e distante da realidade. Por outro lado, muitos espectadores defenderam a forma "irreal" de abordagem, justificando que uma novela tem a liberdade para tratar a temática com a carga ficcional que lhe couber. Caso contrário, não seria novela.

E, quando se fala no audiovisual na escola, outra questão importante a ser tratada diz respeito de como esta linguagem é utilizada, que pode até ser bastante recorrente em sala de aula, mas seu uso é limitado. Champangnatte e Nunes (2011) analisaram em pesquisa que os professores utilizavam as mídias como recurso ilustrativo aos conteúdos que trabalhavam, servindo apenas como complemento. As atividades envolvendo o audiovisual não geravam discussões, leitura crítica, nem tampouco questionamentos. "O uso da mídia em sala de aula que mais predominou foi a utilização como ilustração, tanto na utilização do vídeo quanto da 
O audiovisual como fonte de informação na escola: desafios para a media literacy

internet. Nesse tipo de abordagem, a mídia é usada para exemplificar determinados pontos de um conteúdo trabalhado" (CHAMPANGNATTE; NUNES, 2011, p. 32).

É interessante, portanto, salientar como um produto da mídia pode e deve ser trabalhado não somente dentro de uma perspectiva da temática, nem de mera ilustração, mas do ponto de vista da leitura crítica. Saber que a telenovela é uma forma de representação da realidade, que foi formulada para uma determinada audiência e que manipula uma linguagem específica, por exemplo, enriquece as interpretações e os sentidos que damos a essas produções. Pois, para Kuhlthau (2004), ser alfabetizado visualmente corresponde à capacidade de dominar a habilidade de interpretar o que é visto. "Os alunos começam a entender a linguagem televisiva e a desenvolver uma postura crítica diante da natureza das informações veiculadas pela televisão" (KUHLTHAU, 2004, p. 190). Para a autora, a discussão das produções audiovisuais leva ao desenvolvimento da capacidade para avaliar e selecionar programas.

Assim, ao trabalhar com o filme Pocahontas, por exemplo, dentro de uma perspectiva histórica e como fonte de pesquisa, não somente este viés deve ser considerado. Ao considerar tal filme uma fonte secundária - a qual passou por edições e interpretações - o ideal é que se destaquem as possíveis intenções e os objetivos que ocasionaram a produção desse longa metragem. Assim, conforme Farias Júnior (2014):

[...] aconselhamos que projetos pedagógicos com tais fontes não sejam propostos como reflexos diretos do passado, mas como uma versão que utiliza alguns elementos do passado. A liberdade para criar enredos e justapor aspectos históricos anacrônicos se deve ao fato de que esses gêneros televisivos foram produzidos para atuar como uma forma de entretenimento e, portanto, não podem ser concebidos como um relato histórico, já que o processo de construção dessas mídias não está ancorado em leituras sobre as fontes históricas do momento histórico que retratam.

Dado o exposto, constata-se que não se produz um olhar crítico sem desenvolver no aluno a competência midiática para que seja possível identificar o processo midiático em que a narrativa está envolvida. A construção da leitura crítica ajuda o espectador, no caso de um filme, compreender que o trabalho de filmagem e montagem, a escolha dos personagens, o roteiro, tudo passa por um viés ideológico, podendo estar ligado a certos valores e interesses políticos, sociais, religiosos, científicos, entre outros aspectos que caracterizam esse tipo de fonte midiática. 
Mariana Pícaro Cerigatto e Helen de Castro Silva Casarin

Portanto, cabe discutir como são construídas essas representações, com base no processo de produção midiática, a fim de estabelecer um debate de ideias e de diferentes vieses interpretativos.

A seguir, há a discussão sobre a leitura do audiovisual, e, posteriormente, sobre os conceitos-chaves, ferramentas metodológicas para o trabalho com a media literacy, essenciais para a apropriação dos elementos que compõem um texto audiovisual, visando à sua compreensão e entendimento dentro do processo midiático.

\section{A integração das diversas formas de ler e o papel da biblioteca}

O ler e o escrever modificam-se conforme a época, e novas demandas surgem. Quando se fala em leitura do audiovisual, logo é lembrado que as pessoas estão imersas em uma verdadeira tensão entre tecnologias antigas de leitura, como o livro impresso, e as tecnologias de leitura como o computador, celulares, tablets, todos centrados na leitura digital, online.

E, ainda, quando se fala na crise das bibliotecas, o seguinte discurso é mantido: de que os livros estão sendo apagados pelas novas mídias. Na verdade, esse cenário reforça o quão é urgente que a biblioteca integre a ela todas as tecnologias e mídias, já que as pessoas estão lendo não somente mais através dos livros impressos.

Tyner (1998) sublinha que as formas eletrônicas não estão corroendo nem "dissipando" as mídias impressas, como se acredita no senso comum.

\footnotetext{
A história demonstra que as tecnologias de leitura afloram e imergem, dependendo de um conjunto maior de circunstâncias. As diversas formas de leitura se sobrepõem, coexistem e mudam de maneira simbiótica. A cultura impressa não eliminou a tradição oral. $\mathrm{O}$ rádio, a TV e o computador incorporam as convenções impressa e oral, e não conseguiram acabar com os livros. De fato, as vendas de livro têm se mantido altas. O que ocorre é que as mudanças históricas nas ferramentas de leitura mudam as concepções sobre o que significa ser alfabetizado - uma questão muito mais embaraçosa e complicada (TYNER, 1998, p.13)
}

De acordo com Cerigatto e Siqueira (2008), essas novas formas de leitura colocam em pauta questões sobre o modo como o público usa e dá sentido ao ato de ler, como seleciona e usa as unidades, elementos de um texto na sua forma, conteúdo e contexto.

A tese de que os meios eletrônicos corrompem a leitura veio junto com a disseminação da televisão. Kuhlthau (2004) sublinha que a leitura e a televisão, por exemplo, não estão em competição um com o outro. A autora considera importante valorizar a experiência que cada 
meio desse proporciona, tanto o livro como o audiovisual. São experiências diferentes, porém compatíveis. Segundo ela:

\begin{abstract}
A televisão pode estimular a leitura de livros e a leitura pode levar a criança a se interessar por um programa de televisão. Quando algum livro é adaptado para a televisão, as crianças que o leram geralmente mostram-se ansiosas para ver o programa. Depois que o programa vai ao ar, há sempre uma grande demanda pelo livro por parte de crianças cujo interesse é despertado. Entretanto, há um aspecto em que as duas mídias estão em competição: o tempo de que a criança dispõe. Através de programa da biblioteca as crianças podem ser ajudadas a tomar decisões de que forma gastar o tempo e como fazer escolhas mais competentes do que irão assistir (KUHLTHAU, 2004, p. 151-152).
\end{abstract}

A autora reconhece críticas à televisão, especialmente por ser um meio que induz a atitudes e que incentiva o consumo acrítico. Ela ainda cita questões da violência e descriminação, por vezes, disseminadas por este meio. Mas pondera que a televisão constitui uma fonte de fantasia e entretenimento, além de informação. Assim sendo, os educadores não devem tratar a televisão como adversária, pois, realmente, há como aliá-la ao processo pedagógico, dentro de um projeto que estimule um olhar crítico e reflexivo.

Chartier (2007) acha que as novas formas de ler podem, na verdade, ajudar a manter a cultura escrita. "[...] a tecnologia faz circular os textos de forma intensa, aberta e universal e, acredito, vai criar um novo tipo de obra literária ou histórica" (CHARTIER, 2007, p. web). O pesquisador ainda ressalta que as formas de produção, transcrição e transmissão de texto coexistem.

Descentralizar a leitura do eixo verbal e considerar as leituras do não verbal, assim como desenvolver a competência leitora para ler os mais variados textos é também o que defende o próprio Plano Nacional do Livro e da Leitura (PNLL): "ao reafirmar a centralidade da palavra escrita, não se desconsidera a validade de outros códigos e linguagens, as tradições orais e as novas textualidades que surgem com as tecnologias digitais" (BRASIL, 2014, p. 17). E ainda:

No contexto atual, é imperativo que a leitura seja tratada no diálogo com as diversas tecnologias de gravação, entre as quais o livro se encontra. Como defende Renato Janine Ribeiro, a maneira adequada de difundir a leitura no Brasil não é a de sua "tradição", mas aquela que considera que o sujeito contemporâneo só consegue ser interativo com a mídia sendo, ele mesmo, "multimeios", necessitando da leitura para sê-lo. No mundo de hoje, não apenas a prática leitora deve passar pelo uso das tecnologias de informação e comunicação, mas o usuário dessas tecnologias deve desenvolver, por intermédio da família, da escola e de uma sociedade leitora, a prática de leitura. Neste sentido, deve-se ter atenção às questões contemporâneas acerca dos direitos autorais, fortemente impactados pelas novas possibilidades tecnológicas e seus avanços em termos de possibilidade de gravação e cópia (BRASIL, 2014, p. 17). 
Mariana Pícaro Cerigatto e Helen de Castro Silva Casarin

Assim, hoje, quando se fala de apropriação crítica de informação e necessidades informacionais, temos que considerar a necessidade de alfabetização das novas formas de ler, ampliando nosso conceito de leitura. Segundo Almeida Júnior (2006), atravessamos uma era em que se perpetua a multimídia, que, além do texto escrito, engloba a imagem fixa, a imagem em movimento, e o som. Segundo o autor, as pessoas são analfabetas na leitura dessas outras mídias (e linguagens), por achar que não existe a necessidade de aprendizado dessas linguagens, que é algo natural. "A escola, por sua vez, também não se preocupa com elas. Não há uma cartilha para o aprendizado delas. É importante lembrar que elas possuem linguagens próprias, específicas e sua leitura precisa do conhecimento dessas linguagens pra se concretizar, para se efetivar" (ALMEIDA JUNIOR, 2006, p. 53)

E como a escola pode ampliar seu conceito de leitura, contemplando o desenvolvimento da competência leitora, que depende da competência informacional e midiática? Ressalta-se aqui a importância das bibliotecas, que devem agregar o ensino e aprendizagem de competências. Contudo, é importante expandir o conceito da biblioteca e defender sua inserção no ambiente escolar não somente como espaço e quantidade de acervo. De acordo com Casarin (2014), o trabalho desenvolvido nas bibliotecas pode estar alinhado ao contexto atual das TIC, que tem impacto da aprendizagem dos alunos. Lanzi (2011) defende a inclusão das TIC na biblioteca escolar de modo a promover a dinamização de seus espaços físico e digital para a construção colaborativa do conhecimento. Assim, uma biblioteca escolar mais atuante e em consonância com as atuais necessidades de aprendizagem poderia promover e diversificar as práticas de leitura e de busca de informação, que hoje vão muito além do livro impresso.

Diante destas considerações, cabe, portanto, a reformulação do papel da biblioteca. Garcia-Quismondo e Cuevas Cervero (2007) propõem que as bibliotecas se tornem centros dinâmicos, com uma nova configuração de espaço, um novo conceito de serviço que traz a escola para o mundo real:

La idea de una acción formadora que ha de mantenerse a lo largo de la vida ha sustituido, en los últimos años, al concepto tradicional de educación en una etapa concreta de la vida. Para conseguir ese objetivo de continuidad habrá que unir, por una parte, las políticas educativas y por otro las vías no oficiales de aprendizaje. En esta unión las nuevas Bibliotecas Escolares pueden desempeñar um papel importantísimo, que no ha de limitarse a una mera interacción con el sistema escolar. Deben ser centros dinámicos, con un nuevo espacio-entorno y um innovador concepto de servicios que acerque la escuela al mundo real, que la enriquezca y la haga accesible a todos los ciudadanos, favoreciendo la igualdad. (GARCÍAQUISMONDO; CUEVAS CERVERÓ, 2007, p. 58) 
O audiovisual como fonte de informação na escola: desafios para a media literacy

Considerando, assim, que a biblioteca escolar tem um papel fundamental para a aprendizagem dos novos modos de ler e das novas linguagens e mídias, e pode ser um lugar muito além de "depósito de acervo"; e ainda, ao conceber a biblioteca como centro dinâmico para ensino e aprendizagem, também associamos sua função como desenvolvedora da competência informacional e midiática, dentro de uma perspectiva que preza pelo aprendizado ao longo da vida, algo que, inclusive, tem merecido atenção por parte de organismos como a Organização das Nações Unidas para a Educação, Ciência e Cultura (Unesco) em diretrizes e políticas mundiais para os próximos anos.

\section{A competência midiática e a leitura crítica do audiovisual}

Ao longo do artigo, destacaram-se as produções audiovisuais e seu valor como fonte de pesquisa escolar. Foi ainda mencionada a importância de diversificar a leitura e o desenvolvimento da competência leitora, assim como a necessidade de reformular o papel das bibliotecas. Foi frisado o quanto pode ser considerada errônea a crença de que as mídias digitais/eletrônicas são uma ameaça à leitura do livro impresso. Mas como fazer a leitura crítica do audiovisual para poder melhor utilizá-lo como fonte de pesquisa?

Antes, é importante sublinhar que se trata de desenvolver a competência midiática, que está relacionada à competência informacional. Umas das instituições que defende a união dessas competências é a Nações Unidas para a Educação, Ciência e Cultura (Unesco), que em recente publicação (WILSON et al., 2013) propõe um currículo do que ela chama de alfabetização midiática e informacional (AMI) na formação de professores. $\mathrm{O}$ documento explora atividades envolvendo uma gama de provedores midiáticos e de informação, desde bibliotecas até a internet.

A competência informacional está relacionada com a competência midiática aqui também. Em uma situação de pesquisa escolar, por exemplo, saber que o cinema, a indústria cinematográfica age acordo com interesses ideológicos, de um determinado perfil de audiência etc. é uma das necessidades informacionais quando usamos filmes, por exemplo, como fontes. Afinal, é preciso saber avaliar a "espécie" de informação que encontraremos em uma determinada mídia - saber que ela é uma fonte secundária, por exemplo, que traz informações que passaram por uma interpretação e por uma edição. E, neste processo, podemos recorrer à media literacy, que irá explicar como se produz informação em um 
veículo de comunicação de massa; como acontecem essas edições, filtros etc. Segundo Wilson et al. (2013, p.18):

Por um lado, a alfabetização informacional enfatiza a importância do acesso à
informação e a avaliação do uso ético dessa informação. Por outro, a alfabetização
midiática enfatiza a capacidade de compreender as funções da mídia, de avaliar
como essas funções são desempenhadas e de engajar-se racionalmente junto às
mídias com vistas à autoexpressão.

Após a breve discussão sobre as competências, o foco será discorrer sobre o desenvolvimento da(s) habilidade(s) necessária(s) para ler criticamente produções audiovisuais, ainda mais as consideradas "massivas". Existe um percurso metodológico para fazermos a leitura crítica de novelas, filmes, seriados, desenhos animados etc.

Podemos pontuar que a eficácia de comunicação dos meios eletrônicos, em particular da televisão, e tão bem o cinema, deve-se à capacidade de articular e sobrepor a combinação de linguagens distintas, que inclui imagens, falas, música, escrita, dentro de uma narrativa corrente, "uma lógica pouco delimitada, gêneros, conteúdos e limites éticos pouco precisos, o que lhe permite alto grau de entropia, de flexibilidade, de adaptação à concorrência, a novas situações" (MORAN, 2005, p. 97). E ainda:

Televisão e vídeo combinam a dimensão espacial com a sinestésica, ritmos rápidos e lentos, narrativas de impacto e de relaxamento. Combinam a comunicação sensorial com a audiovisual, a intuição com a lógica, a emoção com a razão. A integração começa pelo sensorial, o emocional e o intuitivo, para atingir posteriormente o racional. Exploram o voyeurismo e mostram até a exaustão planos, ângulos, replay de determinadas cenas, situações, pessoas, grupos, enquanto ignoram a maior parte do que acontece no cotidiano. (MORAN, 2005, p. 98)

O intuito de expor esses argumentos é mostrar que a leitura com o mundo visual exige certas habilidades para a compreensão e a interpretação. "Caso o educador adote o pressuposto de que a imagem em si é suficiente para seu adequado entendimento, pode favorecer uma atitude passiva diante das mensagens transmitidas, cada vez de forma mais intensa, por meio audiovisual" (GARCEZ, 2005, p. 107).

Diferentemente do texto impresso, que por muitas vezes estimula a criação de imagens mentais, a imaginação, o texto visual já fornece imagens prontas, as informações são devidamente ilustradas. Contudo, em contato com essas informações aparentemente perceptíveis, há muitas outras percepções que não estão tão explicitas, que são ideológicas, e que dependem de uma pessoa que saiba captar, compreender, interpretar, criticar, responder, concordar ou discordar do que é posto na telinha. Isso exige diversas habilidades que a escola e a biblioteca podem ajudar a desenvolver.

Bibl. Esc. em R., Ribeirão Preto, v. 3, n. 2, p. 31-52, 2015. 
O audiovisual como fonte de informação na escola: desafios para a media literacy

São habilidades relacionadas à observação, à atenção, à memória, à associação, à análise, à síntese, à orientação espacial, ao sentido de dimensão, ao pensamento lógico e ao pensamento criativo. Elas nos permitem perceber como os elementos da linguagem visual foram organizados: formas, linhas, cores, luzes, sombras, figuras, paisagens, cenários, perspectivas, pontos de vista, oposições, contrastes, texturas, efeitos especiais, etc. E perceber também como esses elementos estão associados a outros, como a música, as ideias, a história, a realidade, por exemplo. (GARCEZ, 2005, p. 107).

Essa discussão nos remete à ideia de que, o tempo todo, a mídia nos coloca em contato com representações de mundo, muitas vezes que competem entre si. Essas representações remetem a posições e valores propagados por diversos meios, e o modo como tais posições e valores específicos são trazidos à tona e mostrados como universais e objetivos acontece através de recursos da linguagem (CERIGATTO; SIQUEIRA, 2008). Deve-se mostrar, nesse sentido, o modo como a linguagem cria o sentido, qual é a intenção do autor ao usar a linguagem desse modo etc. (CERIGATTO; SIQUEIRA, 2008). "Em um momento 'determinado', a estrutura emprega um código e produz uma 'mensagem'; em outro momento determinado, a 'mensagem' desemboca na estrutura das práticas sociais pela via de sua decodificação" (HALL, 2003, p. 390).

Portanto, o código empregado para produzir a mensagem é um dos aspectos que ajuda a gerar o sentido em uma narrativa audiovisual. Cada plano ou ângulo de filmagem escolhido tem uma carga dramática. Pode-se focar a boca de um personagem para dizer que este é tagarela, por exemplo. Assim como a linguagem, outros conceitos constroem as representações de mudo geradas pelas mídias, que podem ser trabalhados em atividades didáticas, conforme propõe o Quadro 1:

\section{Quadro 1 - Conceitos-chave da mídia-educação}

\begin{tabular}{|c|l|}
\hline Conceitos-chave & \multicolumn{1}{|c|}{ Objetivos } \\
\hline Linguagem & $\begin{array}{l}\text { Criar atividades que ajudem o estudante a experimentar a linguagem } \\
\text { midiática e, assim conhecê-la por dentro; }\end{array}$ \\
\hline Instituições de mídia & $\begin{array}{l}\text { Simular e produzir conteúdos aplicando rotinas de produção profissional } \\
\text { para compreender em que medida o produto final é mais resultado de } \\
\text { práticas institucionalizadas do que uma suposta capacidade que a mídia } \\
\text { tem de refletir a realidade como ela é; }\end{array}$ \\
\hline Audiência & $\begin{array}{l}\text { Compreender o comportamento da audiência que, basicamente, negocia } \\
\text { significado com a mensagem. Na prática, algumas mensagens são } \\
\text { interpretadas exatamente do modo como seus autores queriam que fosse, } \\
\text { enquanto outras são interpretadas de modos alternativos e até } \\
\text { completamente inesperados. Desse estudo, ao menos potencialmente, } \\
\text { emerge uma compreensão do poder relativo das mídias, que não deve ser } \\
\text { nem sub, nem super estimado. Compreendido já é o bastante para a } \\
\text { mídia-educação; }\end{array}$ \\
\hline
\end{tabular}

Bibl. Esc. em R., Ribeirão Preto, v. 3, n. 2, p. 31-52, 2015. 
Mariana Pícaro Cerigatto e Helen de Castro Silva Casarin

\begin{tabular}{|l|l|}
\hline Representação & $\begin{array}{l}\text { Aprender a avaliar criticamente o modo como os recursos da linguagem } \\
\text { e as rotinas de produção resultam em valores comumente associados a } \\
\text { sujeitos, hábitos, instituições. Ao comparar (com metodologia) o modo } \\
\text { como mensagens diferentes apresentam o mesmo assunto, os estudantes } \\
\text { têm a oportunidade de se afastar das mídias e observá-las "de cima". Tal } \\
\text { procedimento cria as bases para uma análise crítica, que compreende a } \\
\text { mídia como representação e não como cópia da realidade. }\end{array}$ \\
\hline
\end{tabular}

Fonte: Siqueira (2012)

Este quadro norteia o trabalho didático com os meios de comunicação. Os conceitos dão bases para atividades que exploram essas quatro dimensões da mídia: linguagem, instituições de mídia, audiência e representação.

Para exemplificar: Ao trabalhar com um filme como fonte de pesquisa, o professor pode investigar, junto aos alunos, a linguagem que o filme usa para criar significado e reforçar seu gênero e mensagem. Ao identificar esses elementos (planos, ângulos, a sonoplastia etc.), os alunos conseguem melhor compreender e apreender os significados, o que pode ajudar a alcançar uma melhor interpretação. O espectador crítico ainda é capaz de identificar que aquele filme pertence a uma instituição de mídia, e que está ligado a uma determinada rotina de produção profissional. Uma notícia transmitida por um telejornal é resultado de uma prática institucionalizada e não da realidade.

Um conceito-chave importante é o da audiência. Todo produto da mídia de massa gira em torno de um público-alvo. A partir disso, é possível começar a compreender os motivos pelos quais tal filme explora determinada linguagem: porque quer causar identificação com a audiência que pretende atingir.

E, finalmente, chegamos à representação. A partir disso, entendemos que a novela veiculada pela TV, o filme do cinema e outras produções estão ligados a certos sujeitos, hábitos, valores, instituições. Assim, a comparação de como o cinema aborda a Segunda Guerra Mundial, com um livro, é uma excelente oportunidade de leitura crítica, um exercício que cria as bases para uma análise crítica, que compreende a mídia como representação e não como cópia da realidade.

\section{O audiovisual no ciberespaço: transmídia, remix e outros fenômenos}

$\mathrm{O}$ artigo, até agora, se delineou nas fontes audiovisuais usando exemplos vindos da televisão e do cinema, dois grandes e tradicionais meio de comunicação de massa. E a 
O audiovisual como fonte de informação na escola: desafios para a media literacy

manifestação do audiovisual na internet? Como identificar esses fenômenos? A pretensão é explanar sobre alguns deles, que também podem virar referência de fontes para os alunos.

Primeiramente, é importante destacar que a leitura, diante o cenário digital - mediada por celulares, tablets, computadores e a internet, se dá de forma fragmentada. Por isso, o perfil do leitor na internet exige poder de seleção e rapidez cada vez maiores. Diferentemente da mídia de massa e tradicional, em que a informação já vem "pronta", sem necessidade de seleção. O livro impresso, por exemplo, dá ao leitor a percepção de totalidade, coerência e identidade.

Lévy (1993) sustenta que o hipertexto muda o pensamento. Esse novo ambiente traz inúmeras possibilidades por meio da navegação de links. A leitura não é mais linear e fechada. São dinâmicas, abertas, exigem muita seletividade. E isso vale também para o texto audiovisual na internet.

Assim, é importante ressaltar que o ciberespaço detém de códigos e estruturas próprias. Em seu campo linguístico, o ciberespaço impulsiona uma constante evolução da língua, assim como surgem novos signos adaptados ao meio virtual. Portanto, não é possível apenas pensar que a internet "transporta" a linguagem massiva da televisão. Há outros fenômenos que surgem em meio às possibilidades de produção e edição de informações na web.

Segundo Martín-Barbero (2009), há uma reinvenção de gêneros produzidos pelos meios. A interface da televisão com a internet viabiliza uma interação, uma mistura que desestabilizam os discursos próprios de cada meio - que ele chama de "formas mestiças de comunicação". "Um exemplo de forma mestiça de comunicação é o da televisão quando assume uma comunicação integrada com a internet”. (GONÇALVEZ, 2011, p. 31). Um exemplo é o blog da personagem Luciana, que foi interpretada pela atriz Aline Moraes, na telenovela "Viver a Vida", exibida por uma emissora brasileira entre 2009 e 2010. "A personagem Mia cria um blog para a irmã Luciana, com o intuito de registrar a sua intimidade e a evolução do seu tratamento como tetraplégica. O blog 'Os sonhos de Luciana' é uma extensão da trama da telenovela" (GONÇALVEZ, 2011, p. 31).

Assim, é percebido algo inédito: a mídia de massa combinando suas formas de fazer comunicação com as novas mídias sociais, justamente para ampliar seu público e estender suas narrativas em diferentes plataformas. Essas formas mestiças de comunicação estão 
Mariana Pícaro Cerigatto e Helen de Castro Silva Casarin

relacionadas com as narrativas transmídias. "Uma história transmídia desenrola-se através de múltiplas plataformas de mídia, com cada novo texto contribuindo de maneira distinta e valiosa para o todo" (JENKINS, 2009, p.138).

A linguagem audiovisual está muito presente nesses fenômenos. A "TV na internet" é o YouTube, que diversifica os gêneros possíveis de produções audiovisuais. Blogueiros e seus vídeos viram referência para o público adolescente. Curtas metragens, seriados, entre outras produções, são pensadas para o ambiente online. A linguagem do vídeo também se reinventa e, graças aos usuários mais habilidosos, ganha outros formatos.

Um ponto importante a ser observado dentro de práticas comunicacionais é o remix, o “[...] conjunto de práticas sociais e comunicacionais de combinações, colagens, cut up de informação a partir de tecnologias digitais" (LEMOS, 2005, p.01). “O remix tem suas bases nas misturas, no sincretismo e no pluralismo cultural e se traduz pela possibilidade de apropriação, de desvio e de criação livre a partir de diversos formatos, modalidades e tecnologias" (GONÇALVEZ, 2011, p.32).

Há vários exemplos de produções na web, inclusive audiovisuais, que seguem os propósitos de remix. Podemos citar as produções do criador da sátira "Dilma Bolada", personagem fictício que possui perfil no Facebook, Twitter, canal no YouTube etc. Em várias montagens, como em vídeos, há misturas de cenas da presidente com conteúdos já existentes, formando um novo conteúdo, por vezes, muito criativo.

O remix pressupõe a liberdade de manipular o conteúdo já existente para criar um
novo conteúdo. O conteúdo remixado revela as habilidades do público com as
ferramentas que a tecnologia digital oferece. Entretanto, esse tipo de produção
independente coloca em tensão os remixers e a indústria cultural no que diz respeito
aos direitos autorais (GONÇALVEZ, 2011, p.33).

Observa-se que a prática do remix, muito presente em produções audiovisuais da web, cria um novo conteúdo, que se apropria de ícones e signos presentes na cultura massiva, mas mistura-os com elementos da comunicação possibilitada pelo ciberespaço. Assim, a prática do remix representa uma verdadeira quebra de regras que foge ao controle da indústria cultural e dos meios de comunicação de massa. Assim, os "remixers" revelam-se numa situação de tensão diante o conteúdo protegido por copyright.

Esse cenário reforça as três leis que sustentam a cibercultura, segundo Lemos (2009). A primeira delas diz respeito à liberdade do polo de emissão: 
O audiovisual como fonte de informação na escola: desafios para a media literacy

A liberação do polo de emissão e as facilidades de manuseio das tecnologias digitais promoveram uma cultura mais participativa, onde todas as pessoas, com mínimos recursos, podem divulgar obras de arte, textos, notícias, filmes e músicas para um número amplo de pessoas conectadas à rede mundialmente (GONÇALVEZ, 2011, p. 81).

A segunda lei, do princípio de conectividade generalizada (conexão em rede), prioriza o conectar, compartilhar. Esse fator de conectividade nos remete à constante troca de informações e arquivos da web, que sem a conexão em rede seria inviável. É assim que observamos o quanto facilmente se alastram as produções audiovisuais pela internet:

[...] é da própria disponibilização de conteúdo, feita pelos usuários que ocupam um dado ponto, que os "remixers" vão retirar a matéria prima para poder transformá-la em um novo produto. Tendo por base o produto trailer, o sujeito X disponibilizará um filme em um banco de dados na internet. O sujeito Y, fã daquele filme, poderá, pois, fazer o download do filme e transformá-lo, por meio da utilização de softwares, em um trailer, e postar o produto de sua edição em canais como o YouTube. O sujeito Z, por sua vez, obtém o filme no banco de dados, posta esse filme inteiro no YouTube e ainda faz uma versão de um trailer que, passando por um processo de edição, dando àquele filme que era de ação, uma conotação de comédia, graças à utilização de fragmentos específicos que possam passar esse sentido, postando o também no canal como vídeo relacionado ao filme na íntegra, ao trailer feito pelo sujeito $\mathrm{Y}$ e a outros filmes de comédia. Práticas assim, de disponibilização, trocas e geração de novos conteúdos são o que caracterizam a prática da conexão generalizada [...]. (CAVALCANTI, 2013, p. 6)

E, finalmente, a terceira lei gera a reconfiguração cultural, que aponta para significativas mudanças na indústria cultural e nas práticas comunicacionais. São novos formatos midiáticos e novos modos de produção, circulação e recepção de conteúdos culturais. Os professores e os profissionais da informação precisam também estar atentos a essas manifestações e considerar que essas produções que circulam pela web - especialmente os vídeos, com milhões de acessos - também estão virando fortes referências e fontes de informação cotidianas na vida de jovens e adolescentes, considerando que ao audiovisual ainda representa grande apelo.

Da mesma maneira que as formas audiovisuais tradicionais, é possível incorporar essas novas produções de remixers - muitas ligadas ao humor e entretenimento - como fontes de informação didáticas? Sim, desde que o professor saiba contextualizar a produção, saiba comparar essas fontes com outras, e faça uma análise da linguagem, da audiência, das narrativas e das representações de mundo que geram essas novas produções. É um novo campo a ser explorado pela media literacy. 


\section{Considerações finais}

Por vezes, somos surpreendidos pelas habilidades dos jovens com a tecnologia e a familiaridade com o audiovisual. Hoje em dia, esse público é muito competente para "baixar" músicas, tirar fotos, "baixar" filmes etc. E, em várias ocasiões, vemos o quanto o audiovisual está presente na vida das novas gerações.

Contudo, esses mesmos jovens conhecem muito pouco sobre a linguagem e a técnica de produção de sons, vídeos e textos. Por mais que tenham habilidades de acesso, faltam habilidades para analisar e avaliar criticamente esses conteúdos.

A televisão, o cinema e, mais recentemente, a internet, são fontes importantes de informação e conhecimento de milhares de crianças, adolescentes e jovens. É por meio de um filme, por exemplo, que o público pode ter contato pela primeira vez com um determinado assunto. A novela pode explorar temas diversos da atualidade, que invadem as casas e as famílias, onde também estão inseridos esses jovens. Os blogueiros contemporâneos no YouTube falam de assuntos de política, dia a dia e são seguidos por milhares de pessoas.

Entretanto, muitas vezes, essa relação com o audiovisual é vista apenas dentro de uma perspectiva de entretenimento. É fundamental que os alunos aprendam a refletir o que as imagens representam, e identifiquem os meios audiovisuais como possibilidades de construção de conhecimento, por meio dos exercícios críticos para a interpretação das mensagens visuais, dentro da concepção da media literacy e do desenvolvimento da competência midiática.

Por parte do professor, é necessário que se reconheça o potencial didático dos meios audiovisuais. Por que, quando se vai à biblioteca, o trabalho geralmente é restrito somente aos livros impressos? Pode o professor fazer um projeto que contemple o acesso a várias mídias. Como foi colocado neste artigo, através de Kuhlthau (2004), o audiovisual é importante fonte de informação. É possível analisar sua linguagem, examinar como o cinema, a televisão etc. representam uma temática, como fonte histórica, como apreciação estética etc.

Fica aqui o reforço do trabalho com a mídia como fonte de pesquisa, mas não somente como instrumento ilustrativo ou justificador do texto didático, ou do discurso do professor. Geralmente, quando o professor decide por utilizar uma fonte audiovisual, usa como algo secundário, pois a compreensão desta fonte, por vezes, se delimita a uma mera ilustração ou complemento do tema abordado.

Bibl. Esc. em R., Ribeirão Preto, v. 3, n. 2, p. 31-52, 2015. 
O audiovisual como fonte de informação na escola: desafios para a media literacy

É imprescindível, portanto, que a escola assuma um trabalho mais crítico com os meios de comunicação como fonte escolar, abrindo a discussão para que os alunos façam verdadeiras releituras. Pela importância social, cultural e econômica da mídia nas sociedades modernas, é de extrema necessidade, conforme nos indica Buckingham (2003), que se fomente uma visão mais ampla do universo midiático, já que as mídias estão presentes no nosso cotidiano, são formadoras de opinião, e nos fornecem, a todo momento "recursos simbólicos", que dão bases para nossas interpretações e representações de mundo, assim como para definir nossas identidades. "Espera-se que a escola (en)foque o mundo audiovisual, faça da TV objeto de estudo, conheça-lhe linguagem, programação, condições de produção e de recepção e a incorpore pedagogicamente" (CARNEIRO, 2005, p. 103).

Assim, a escola, os educadores e as bibliotecas escolares têm como tarefa assumir um dos maiores desafios contemporâneos, que é discutir, analisar, avaliar etc. o que é veiculado pela televisão, pelo cinema, pela internet e por outras mídias na atualidade. As instituições escolares precisam se viabilizar como espaço crítico em relação às informações e às manifestações advindas dessas mídias. É necessário, portanto, desenvolver um trabalho com a competência informacional e midiática para se apropriar da linguagem audiovisual como fonte de informação e conhecimento, criação, expressão e comunicação.

\section{Referências}

ALMEIDA JÚNIOR, O. F. Bibliotecário escolar: seu perfil, seu fazer. In: SILVA, R. J.; BORTOLIN, S. (Org.). Fazeres cotidianos da biblioteca escolar. São Paulo: Polis, 2006, p. 43-54.

BRASIL. Ministério da Cultura. Caderno do Plano Nacional do Livro e Leitura: PNLL: edição atualizada e revisada em 2014. Brasília, DF. Disponível em:

<http://www.cultura.gov.br/pnll>. Acesso em: 20 set. 2014

BRETAS, M. B. A. S. Televisão. In: CAMPELLO, B.; CALDEIRA, P. T. Introdução às fontes de informação. Belo Horizonte: Autêntica, 2008.

BUCKINGHAM, D. Media education: literacy, learning and contemporary culture. Cambridge: Polity, 2003.

CARNEIRO, V. A televisão e educação: aproximações. In: ALMEIDA, M. E. B.; MORAN, J. M. Integração das tecnologias na educação: salto para o futuro. Brasília: Ministério da Educação, 2005. p.103-105. Disponível em:

<http://portal.mec.gov.br/seed/arquivos/pdf/iniciaissf.pdf>. Acesso em: 01 nov. 2014. 
Mariana Pícaro Cerigatto e Helen de Castro Silva Casarin

CASARIN, H. C. S. Biblioteca escolar no ensino fundamental: em busca de um modelo alternativo. Marília: Programa de Ensino Público da Fapesp, 2014.

CAVALCANTI, I. C. O Trailer remix como ferramenta funcional da cibercultura. Revista Temática, v. 2, n. 9, p.01-11, fev. 2013. Disponível em:

<http://www.insite.pro.br/2013/Fevereiro/trailer_remix_cibercultura.pdf >. Acesso em: 12 nov. 2014.

CERIGATTO, M. P.; SIQUEIRA, A. B. Media literacy: estudando o trailer do cinema no ensino médio. 2008. 90f. Trabalho de iniciação científica (graduação em jornalismo) Universidade do Sagrado Coração, Bauru.

CHAMPANGNATTE, D. M. O.; NUNES, L. C. A inserção das mídias audiovisuais no contexto escolar. Educação em Revista, Belo Horizonte, v. 27, n. 3, p.15-38, dez. 2011. Disponível em: 〈http://www.scielo.br/pdf/edur/v27n3/v27n3a02.pdf〉. Acesso em: 23 nov. 2014

CHARTIER, R. Roger Chartier: "Os livros resistirão às tecnologias digitais". Revista Nova Escola, São Paulo, edição 204, ago. 2007. Entrevista a Cristina Zahar. Disponível em: $<$ http://revistaescola.abril.com.br/lingua-portuguesa/fundamentos/roger-chartier-livrosresistirao-tecnologias-digitais-610077.shtml>. Acesso em: 13 nov. 2014.

FARIAS JÚNIOR, J. P. O uso de fontes audiovisuais e novas mídias no ensino de história antiga na educação básica. História e-história, Campinas, 05 fev. 2014. Publicação organizada com o apoio do grupo de pesquisa Arqueologia Histórica da Unicamp. Disponível em: <http://www.historiahistoria.com.br/materia.cfm?tb=artigos\&id=257>. Acesso em: 05 out. 2014.

GARCEZ, L. H. A leitura da imagem. In: ALMEIDA, M. E. B.; MORAN, J. M. Integração das tecnologias na educação: salto para o futuro. Brasília: Ministério da Educação, 2005. p.107-111. Disponível em: <http://portal.mec.gov.br/seed/arquivos/pdf/iniciaissf.pdf>. Acesso em: 01 nov. 2014.

GARCIA-QUISMONDO, M.; CUEVAS CERVERO, A. Biblioteca escolar para la sociedad del conocimiento em España. Ciência da Informação, Brasília, v. 36, n.1, abr. 2007.

GONÇALVEZ, R. Conteúdos culturais na cibercultura: um estudo do processo de convergência midiática da obra de clarah averbuck. 2011. 103 f. Dissertação (Mestrado) Curso de Letras, Universidade Federal de São João Del Rei, São João Del Rei, 2011. Disponível em: <http://www.ufsj.edu.br/portal2repositorio/File/mestletras/DISSERTACOES_2/conteudos_culturais_na_cibercultura.pdf >. Acesso em: 10 out. 2013.

GREEN, H.; HANNON, C. Their Space: education for a digital generation. Londres: Demos, 2007.

HALL, S. Da diáspora. Belo Horizonte: Editora UFMG, 2003.

JENKINS, H. Cultura da convergência. São Paulo: Aleph, 2009. 
O audiovisual como fonte de informação na escola: desafios para a media literacy

KENSKI, V. As tecnologias invadem nosso cotidiano. In: ALMEIDA, M. E. B.; MORAN, J. M. Integração das tecnologias na educação: salto para o futuro. Brasília: Ministério da Educação, 2005. p. 93-95. Disponível em:

<http://portal.mec.gov.br/seed/arquivos/pdf/iniciaissf.pdf>. Acesso em: 01 nov. 2014.

KUHLTHAU, C. C. Como usar a biblioteca na escola: um programa de atividades para o ensino fundamental. Belo Horizonte: Autêntica, 2004.

LANZI, L. A. C. Apropriação das tecnologias de informação e comunicação em bibliotecas escolares: em busca de um espaço dinâmico. 176 p. Dissertação (Mestrado em Ciência da Informação) - Faculdade de Filosofia e Ciências, Universidade Estadual Paulista, Marília, 2011.

LEMOS, A. Cibercultura e remix. In: SEMINÁRIO “SENTIDOS E PROCESSOS”. São Paulo, Itaú Cultural, agosto de 2005. Disponível em:

http://www.facom.ufba.br/ciberpesquisa/andrelemos/remix.pdf .Acesso em: 20 fev. 2014.

Cibercultura como território recombinante. In. TRIVINHO, E.; CAZELOTO, E. A

cibercultura e seu espelho: campo de conhecimento emergente e nova vivência humana na era da imersão interativa. São Paulo: ABCiber ; Instituto Itaú Cultural, 2009. p. 38-51.

(ColeçãoABCiber). Disponível em:

$<$ http://abciber.org/publicacoes/livro1/a_cibercultura_e_seu_espelho.pdf > Acesso em: 24 fev. 2010.

LÉVY, P. A inteligência coletiva: por uma antropologia do ciberespaço. São Paulo: Loyola, 2003.

MARTÍN- BARBERO, J. As formas mestiças da mídia. Revista Pesquisa FAPESP, ed. 163, set. 2009.

MORAN, J. M. Desafios da televisão e do vídeo à escola. In: ALMEIDA, M. E. B.; MORAN, J. M. Integração das tecnologias na educação: salto para o futuro. Brasília: Ministério da Educação, 2005. p. 97-100. Disponível em:

<http://portal.mec.gov.br/seed/arquivos/pdf/iniciaissf.pdf>. Acesso em: 01 nov. 2014.

PIRES, E. G. A experiência audiovisual nos espaços educativos: possíveis interseções entre educação e comunicação. Educação e Pesquisa, São Paulo, v. 36, n. 01, p.281-295, jan. 2010. Disponível em: <http://www.scielo.br/pdf/ep/v36n1/a06v36n1.pdf>. Acesso em: 12 out. 2014.

SIQUEIRA, A. B. Blog da mídia-educação: curso de extensão forma colaboradores para o projeto Redeci. 2012. Disponível em: <http://medialiteracybrasil.net/>. Acesso em: 02 jul. 2012.

TYNER, K. Literacy in a digital world. Mahwa: Lawrence Erlbaum, 1998.

WILSON, C. et al. Alfabetização midiática e informacional: currículo para formação de professores. Brasília: Unesco, UFMT, 2013. 194 p. 